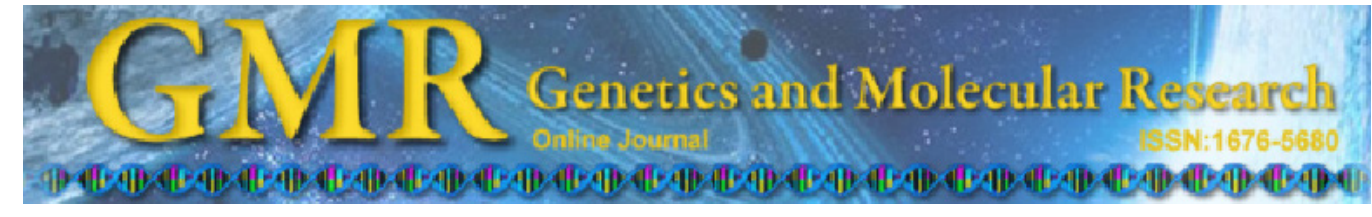

\title{
Genetic diversity of Palestine landraces of faba bean (Vicia faba) based on RAPD markers
}

\author{
R. Basheer-Salimia ${ }^{1}$, M.Shtaya ${ }^{2}$, M.Awad ${ }^{1}$, J. Abdallah $^{3}$ and Y.Hamdan ${ }^{4}$ \\ ${ }^{1}$ Department of Plant Production and Protection, Faculty of Agriculture, \\ Hebron University, Hebron, Palestine \\ ${ }^{2}$ Department of Plant Production and Protection, Faculty of Agriculture, \\ An-Najah National University, Nablus, Palestine \\ ${ }^{3}$ Department of Animal Production and Animal Health, Faculty of Agriculture, \\ An-Najah National University, Nablus, Palestine \\ ${ }^{4}$ Technical and Applied Research Center, Palestine Technical University, \\ Tulkarem, Palestine
}

Corresponding author: R. Basheer-Salimia

E-mail: rezqbasheer@hebron.edu

Genet. Mol. Res. 12 (3): 3314-3323 (2013)

Received January 28, 2013

Accepted March 30, 2013

Published September 3, 2013

DOI http://dx.doi.org/10.4238/2013.September.3.8

\begin{abstract}
Until now, neither phenotypic nor molecular approaches have been used to characterize the landraces of Palestine faba beans (Vicia faba). We used PCR-based RAPD markers to determine the genetic diversity and relatedness among 26 Palestinian faba bean landraces (traditional farmers' varieties) from 8 localities in the West Bank, Palestine. In tests with 37 primers, 14 generated no polymorphic bands, 12 exhibited weak and unclear products, and 11 primers produced good amplification products with high intensity and pattern stability. Ninety-four DNA fragments (loci) were detected, with an average of 8.54 loci per primer and size ranging from 160 to $1370 \mathrm{bp}$. A minimum of 4 and a maximum of 14 DNA fragments were obtained using (OPA-05 and OPA-09) and (BC-261) primers, respectively. The maximum percentage of polymorphic markers was 71.4 (BC-298) and the minimum was 50.0 (OPA-05, $-09,-16)$. The 11 primers exhibited
\end{abstract}


relatively high collective resolving power $(\mathrm{Rp})$ values of 26.316 , and varied from 0.154 for the OPA-09 primer to 5.236 for the BC-261, with an overall mean of 2.392. The primers BC-261, -322, and -298 were found to be the most useful RAPD primers to assess the genetic diversity of Palestinian faba beans, as they revealed relatively high Rp rates (5.236, 3.618, and 3.150, respectively). Based on the Jaccard coefficient, the genetic distance ranged from 0.358 to 0.069 , with a mean of 0.213 . We conclude that the RAPD technique is useful for determining genetic diversity and for developing suitable fingerprints for faba bean landraces grown in Palestine.

Key words: Vicia faba; DNA fingerprinting; Genetic diversity; RAPD

\section{INTRODUCTION}

Faba bean (Vicia faba L.) is the fourth most important cultivated legume crop after field pea, chick pea, and lentil, respectively. Historically, it is one of the oldest crops grown by humans (Zong et al., 2009). The oldest seeds of Vicia faba were found in Jericho Palestine, and date as far back as $6250 \mathrm{BC}$ (Mc-Vicar et al., 2008).

Because of the high nutritional value of its seeds, it is known as a major food and feed legume (Gnanasambandam et al., 2012). Additionally, faba bean provides major benefits to cropping systems and the environment, due to the ability to perform symbiotic nitrogen fixation (Kaur et al., 2012), break disease cycles in the cereal-based rotations (Murray et al., 1988), and control weeds (Schmidtke and Rauber, 2000). Generally, large-seeded faba bean grain is used as food, while medium-sized grain is used as food and feed, with small-sized grain mainly used as feed (Redden et al., 2007).

The 2010 world production of faba bean was 4.3 million tons (FAO, 2010), of which $80 \%$ traditionally came from developing countries (Torres et al., 1993) as a cheap protein-rich food for low-income people, thus partly compensating for the large deficiency in animal protein sources. In Palestine, faba bean is one of the essential legume crops grown mainly under rain-fed conditions. The annual production of faba bean is very low and varies from year to year and from location to location, with a total production of about 3917 tons cultivated on 507 ha (PCBS, 2010).

Genetically, most faba bean genotypes planted in Palestine are landraces, with some minor recently introduced commercial cultivars. In fact, landraces are population mixtures containing a great number of different hereditary types due to their genotypic diversity as well as their adaptation to the change in environmental conditions of their habitat (Kuckuck et al., 1991). The long history of faba bean growth in Palestine and the wide range of climatic conditions under which it is grown, have combined to produce a complex picture in which faba bean landraces and genotypes are either misidentified or called by different names in different areas. In addition, the severe decline of its cultivation due to low yield and yield instability (Gresta et al., 2009) increases the real risk of losing useful genetic resources for any future breeding programs and variety development (De Giorgio and Polignano, 2001). Therefore, it is critical to discriminate between these landraces, both for conservation of plant genetic resources and for purposes of crop improvement. 
Detection and analysis of genetic variation can be achieved either by morphological and/or DNA molecular markers. To date, neither morphological nor molecular approaches have been used to evaluate the landraces of faba bean from Palestine. In this study, we made major advances in understanding the history and genetic variation of faba bean by using molecular genetic analysis.

It is well documented that DNA-based markers are powerful tools to estimate the genetic diversity of plant species, as well as genotype identity. Indeed, molecular markers offer numerous advantages over conventional morphology-based approaches, since they are stable and detectable in all tissues regardless of growth, differentiation, development, or defense status of the cell. In addition, DNA markers are not confounded by the environment or pleiotropic and epistatic effects (Agarwal et al., 2008).

In faba bean, various molecular techniques have been successfully used to assess genetic relatedness and diversity, such as isozyme (Kaser and Steiner, 1983; Mancini et al., 1989), restriction fragment length polymorphism (Torres et al., 1993), inter-simple sequence repeat (Terzopoulos and Bebeli, 2008), amplified fragment length polymorphism (Zeid et al., 2003; Zong et al., 2009), simple sequence repeats (Kaur et al., 2012), and randomly amplified polymorphic DNA (RAPD) methods (Torres et al., 1993; Link et al., 1995). Compared with other molecular techniques, RAPD is based on random amplification of bases from short primers. The use of the RAPD technique offers a simple, fast, efficient, and inexpensive method (Basheer-Salimia et al., 2012). Furthermore, it does not require prior knowledge of the sequences of the markers and can produce abundant polymorphic fragments (Kocsis et al., 2005; Achtak et al., 2009). Therefore, RAPD has become a powerful and accurate tool for analyzing the genetic relatedness and diversity in many species.

The present study is the first attempt to estimate the genetic diversity and relationships between some faba bean genotypes grown in Palestine using PCR-based RAPD molecular markers.

\section{MATERIAL AND METHODS}

\section{Plant materials and DNA extraction}

This study was carried out during the growing season of 2011. A total of 26 faba bean accessions (Table 1) were surveyed covering 8 different localities of the West Bank, Palestine. The climate of the region is a typical Mediterranean climate, with mild temperatures $\left(18-25^{\circ} \mathrm{C}\right)$ and wet conditions $(580-800 \mathrm{~mm} /$ year) in autumn and winter, and with hot and dry summers. Generally, all faba beans are cultivated under rain-fed conditions.

Genomic DNA was extracted from fully expanded fresh leaves from 10 single seedlings (20 days old) of 26 faba bean accessions using the DNeasy Plant Mini kit (Qiagen Inc.).

\section{RAPD primers and PCRs}

A total of 37 RAPD primers (Sigma-Aldrich) were used for the amplification of random DNA banding patterns (Table 2). PCRs were repeated twice and carried out in a $25-\mu \mathrm{L}$ reaction mixture containing: $2.5 \mu \mathrm{L} 30 \mathrm{ng}$ total DNA, $2 \mu \mathrm{L} 5 \mu \mathrm{M}$ primer, $2 \mu \mathrm{L} 200 \mathrm{mM}$ dNTPs 
(Fermentas), $2.5 \mu \mathrm{L}$ 10X Taq buffer, $2 \mu \mathrm{L} 25 \mathrm{mM} \mathrm{MgCl}_{2}$, and $1.5 \mathrm{U}$ Taq DNA polymerase (Hy Labs). Consequently, DNA was amplified by PCR on a Peltier Thermal Cycler-200 (MJ Research Inc., Watertown, MA, USA) and the PCR program was: 1 cycle at $94^{\circ} \mathrm{C}$ for $3 \mathrm{~min}$; 35 cycles at $94^{\circ} \mathrm{C}$ for $1 \mathrm{~min}, 35^{\circ} \mathrm{C}$ for $1 \mathrm{~min}$, and $72^{\circ} \mathrm{C}$ for $1.5 \mathrm{~min} ; 1$ cycle at $72^{\circ} \mathrm{C}$ for $5 \mathrm{~min}$; and then cooling down to $4^{\circ} \mathrm{C}$. Amplified products $(25 \mu \mathrm{L})$ were mixed with $5 \mu \mathrm{L}$ Orange $\mathrm{G}$ loading buffer and analyzed by electrophoresis on $2 \%$ agarose gels (Hy Labs) in 1X TAE buffer at $4 \mathrm{~V} / \mathrm{cm}$ for $4 \mathrm{~h}$, with detection of bands by staining with ethidium bromide (Sigma). A 100-bp DNA ladder was used as a standard molecular weight marker to get an approximate size of DNA fragments (Fermentas). Consequently, amplification was visualized with a UV transilluminator (ImageMaster ${ }^{\circledR}$ VDS).

\section{Data analysis}

For each primer, 3 independent researchers calculated the total number of bands and the number of polymorphic bands to avoid subjective bias. The ability of the most informative primers to differentiate between landraces was assessed by the estimation of their resolving power (Rp) (Prevost and Wilkinson, 1999). Rp has been described as correlating strongly with the ability to distinguish between landraces according to the following formula (Gilbert et al., 1999): $\mathrm{Rp}=\sum \mathrm{Ib}$, where $I b=1-(2 \times|0.5-\mathrm{p}|)$, where $p$ is the proportion of the 26 landraces possessing the I band.

Banding profile data were scored as present (1) or absent (0) for each sample. Afterwards, RAPD bands were transformed into a binary matrix. The data matrix included 2444 entries, 1721 of which were for present loci (1) and 723 for absent loci (0). Next, a genetic distance matrix was estimated based on Jaccard's similarity coefficient using the multilocus fingerprinting data sets containing missing data [FAMD software, version 1.108beta]. A cluster analysis was then performed using the unweighted pair-group method with arithmetic averages (UPGMA) (Schluter and Harris, 2006) and the Tree View software (Win32, version 1.6.6).

\section{RESULTS AND DISCUSSION}

With increasing the number of faba bean varieties, it is difficult to differentiate these varieties based on morphological characters alone, since these characters are either influenced by environmental factors and stage of plant development or reveal limited variation (Terzopoulos and Bebeli, 2008). Therefore, considerable efforts at the molecular level have been undertaken worldwide toward assessment of genetic diversity and relatedness in faba bean (Gnanasambandam et al., 2012). However, very few studies have been done in the Middle East in general, and Palestine in particular.

In the present research, PCR-based RAPDs are the first molecular markers used to determine the genetic diversity and relatedness of 26 unidentified Palestinian faba bean landraces (traditional farmers' varieties) (Table 1). We tested 37 primers: 23 primers generated various banding patterns and 14 primers revealed no polymorphic bands. Eleven primers (29.7\%) produced good amplification products with high intensity and pattern stability (Table 2), and were therefore used in this study. The remaining 12 primers exhibited few, weak and unclear complex amplification products, and were therefore excluded. 
A total of 94 DNA fragments (loci), separated by electrophoresis on an agarose gel, were detected (Tables 2 and 3), ranging in size from 160 to $1370 \mathrm{bp}$. Of these fragments, 59(62.8\%) were polymorphic and $35(37.2 \%)$ were monomorphic. Compared with another Mediterranean study reported by Terzopoulos and Bebeli (2008) using 11 inter-simple sequence repeat markers with 28 faba bean populations (with all amplified bands $150-900 \mathrm{bp}$ and percentage of polymorphism of $69.1 \%$ ), our results revealed a greater range of amplified bands and a somewhat similar percentage of polymorphisms. Indeed, the good level of polymorphism and the determination of specific RAPD markers detected in the present investigation confirmed the efficiency of RAPD molecular markers in detecting polymorphism among Palestinian faba bean landraces.

Table 1. Palestinian Vicia faba L. landraces studied with their collection sites.

\begin{tabular}{|c|c|c|c|c|}
\hline Accession & Accession & Seed size & Collecting site & State \\
\hline VF-1 & Local faba bean & Small & Ras & Qalqelia \\
\hline VF-2 & Local faba bean & Small & Zababdeh & Jenin \\
\hline VF-3 & Local faba bean & Small & Amateen & Nablus \\
\hline VF-4 & Local faba bean & Small & Beit-Ebia & Nablus \\
\hline VF-5 & Local faba bean & Small & Beta & Nablus \\
\hline VF-6 & Local faba bean & Small & Taiaseer & Tubas \\
\hline VF-7 & Local faba bean & Small & Jaious & Qalqelia \\
\hline VF-8 & Local faba bean & Small & Senjel & Rammalla \\
\hline VF-9 & Local faba bean & Small & Qabatia & Jenin \\
\hline VF-10 & Local faba bean & Small & Selet-El-Thaher & Jenin \\
\hline VF-11 & Local faba bean & Small & Showeka & Tulkarem \\
\hline VF-12 & Local faba bean & Small & Tubas & Tubas \\
\hline VF-13 & Local faba bean & Small & Tubas & Tubas \\
\hline VF-14 & Local faba bean & Small & Tulkarem & Tulkarem \\
\hline VF-15 & Local faba bean & Small & Azzoun & Qalqelia \\
\hline VF-16 & Local faba bean & Small & Anabta & Tulkarem \\
\hline VF-17 & Local faba bean & Big & Ain-El-Beda & Tubas \\
\hline VF-18 & Local faba bean & Small & Nablus & Nablus \\
\hline VF-19 & Local faba bean & Small & Nah'leen & Rammalla \\
\hline VF-20 & Local faba bean & Big & Tamoun & Tubas \\
\hline VF-21 & Local faba bean & Small & Dora & Hebron \\
\hline VF-22 & Local faba bean & Big & Al-Khader & Bethlehem \\
\hline VF-23 & Local faba bean & Big & Al-Khader & Bethlehem \\
\hline VF-24 & Local faba bean & Big & Bethlahim & Bethlehem \\
\hline VF-25 & Local faba bean & Small & Yatta & Hebron \\
\hline VF-26 & Local faba bean & Small & Yatta & Hebron \\
\hline
\end{tabular}

\begin{tabular}{|c|c|c|c|c|c|c|c|}
\hline \# & Primer code & Sequence $\left(5^{\prime}-3^{\prime}\right)$ & RAPD total bands & $\begin{array}{l}\text { Polymorphic } \\
\text { bands }\end{array}$ & $\begin{array}{l}\text { Monomorphic } \\
\text { bands }\end{array}$ & $\begin{array}{l}\text { Resolving power } \\
\text { (Rp) }\end{array}$ & $\begin{array}{c}\text { Percentage of } \\
\text { polymorphic markers }\end{array}$ \\
\hline 1 & OPA-16 & AGCCAGCGAA & 10 & 7 & 3 & 2.920 & 70.0 \\
\hline 2 & OPB-11 & GTAGACCCGT & 11 & 7 & 4 & 2.846 & 63.6 \\
\hline 3 & OPA-10 & GTGATCGCAG & 5 & 3 & 2 & 1.922 & 60.0 \\
\hline 4 & OPA- 05 & AGGGGTCTTG & 4 & 2 & 2 & 0.308 & 50.0 \\
\hline 5 & OPA-09 & GGGTAACGCC & 4 & 2 & 2 & 0.154 & 50.0 \\
\hline 6 & OPB-16 & TTTGCCCGGA & 8 & 4 & 4 & 2.540 & 50.0 \\
\hline 7 & BC-322 & GCCGCTACTA & 8 & 5 & 3 & 3.618 & 62.5 \\
\hline 8 & BC-261 & CTGGCGTGAC & 14 & 10 & 4 & 5.236 & 75.0 \\
\hline 9 & BC-298 & CCGTACGGAC & 8 & 6 & 2 & 3.150 & 71.4 \\
\hline 10 & 10 & AGGCGGGTAC & 13 & 8 & 5 & 2.156 & 61.5 \\
\hline 11 & $\mathrm{R}-11$ & GTAGCCGTCT & 9 & 5 & 4 & 1.466 & 55.5 \\
\hline Mean & & & 8.54 & 5.36 & & 2.392 & \\
\hline Total & & & 94 & 59 & 35 & 26.316 & 62.76 \\
\hline
\end{tabular}


Our results also revealed an average of 8.54 loci per primer (Table 3). A close average was also obtained with other legume crops such as pigeon pea using RAPD markers (Yadav et al., 2012). In addition, the maximum percentage of polymorphic markers was 71.4 (BC-298; Figure 1) and the minimum was 50.0 (OPA-05, -09, and -16). Consequently, a minimum of 4 and a maximum of 14 DNA fragments were obtained using OPA-05 and -09 and BC-261 primers (Figure 2), respectively, which indeed implies a small range of alleles per locus as compared to soybean (11-26 alleles per locus) (Kumar and Ali, 2006).

Table 3. Summary of amplification generated by random primers tested in this study.

\begin{tabular}{ll}
\hline Number/frequency & Description \\
\hline 37 & Total number of primers screened with all the 26 faba bean genotypes \\
11 & Number of primers that produced polymorphic bands \\
94 & Total number of bands amplified by the primers that generated polymorphic bands \\
8.54 & Average number of bands per primer \\
59 & Total number of polymorphic bands \\
62.76 & Percentage of polymorphic bands \\
5.36 & Average number of polymorphic bands per primer \\
3 & Total number of primers that produced more than $70 \%$ polymorphic bands \\
32 & Total number of bands produced by these 3 primers \\
23 & Number of polymorphic bands produced by these 3 primers \\
72 & Percentage of polymorphic bands \\
7.67 & Average number of polymorphic bands per primer \\
$160-1370 \mathrm{bp}$ & Average size of the fragments amplified \\
\hline
\end{tabular}

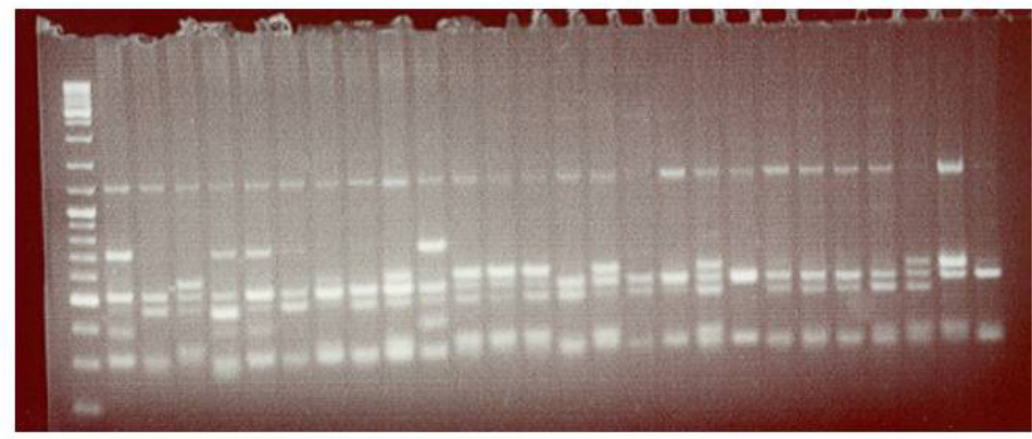

\section{BC-298}

Figure 1. Randomly amplified polymorphic DNA banding patterns generated in 26 Palestinian faba bean landraces using BC-298 primer.

The primers tested exhibited relatively high collective $\mathrm{Rp}$ values of 26.316 and varied from 0.154 for the OPA-09 primer to 5.236 for the BC-261, with an overall mean of 2.392 (Table 2). The primers BC-261, -322 , and -298 were the most useful RAPD primers to assess the genetic diversity since they revealed relatively high $\mathrm{Rp}$ rates $(5.236,3.618$, and 3.150, respectively). In fact, higher Rp rates also establish the effectiveness of RAPD molecular markers in detecting polymorphism among plant species (Basheer-Salimia et al., 2012). 


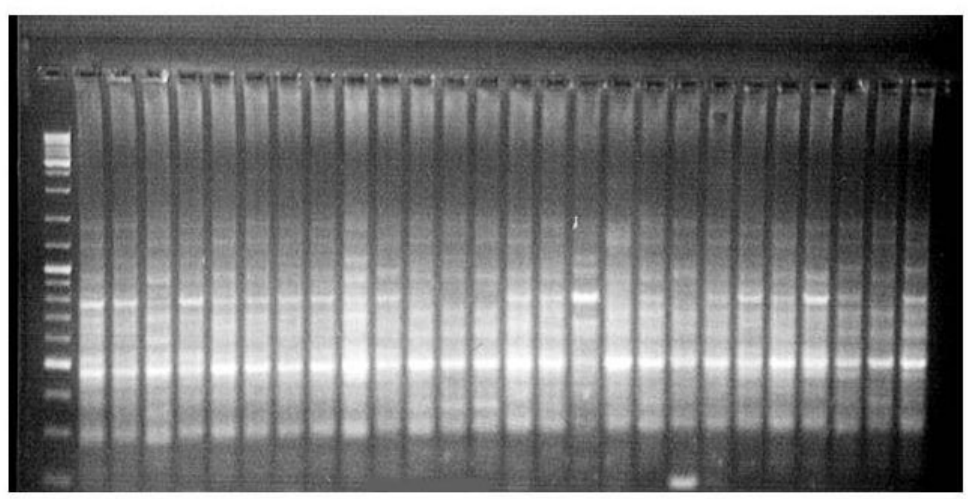

\section{BC-261}

Figure 2. Randomly amplified polymorphic DNA banding patterns generated in 26 Palestinian faba bean landraces using $\mathrm{BC}-261$ primer.

The genetic distances based on the Jaccard coefficient are presented in Table 4 . The genetic distance ranged from 0.069 to 0.358 with a mean of 0.213 . The maximum genetic distance of 0.358 was between landraces 16 and 18 . Whereas, the lowest genetic distance of 0.069 was between landraces 1 and 2, indicating a very close relatedness between the 2 landraces. In general, a high level of similarities (narrow genetic diversity) was found between all faba bean landraces examined. Similar results were reported for other Mediterranean countries by Yahia et al. (2012), who found that the Tunisian faba bean shares a fairly large amount of similarities.

The average genetic relatedness of the genotypes is illustrated in Figure 3. The RAPD UPGMA dendrogram analysis singled out landrace 20 into a separate branch and divided the other landraces into 2 major clusters. Cluster I was composed of 10 landraces (VF-26, VF-10, VF-25, VF-21, VF-14, VF-12, VF-8, VF-2, VF-13, and VF-19), and cluster II was divided into 2 sub-clusters: sub-cluster II.a including 6 landraces (VF-22, VF-9, VF-23, VF-6, VF-24, and VF-17) and sub-cluster II.b containing 9 landraces (VF-1, VF-7, VF-11, VF-18, VF-15, VF-5, VF-16, VF-3, and VF-4).

Our results revealed an incompatible association between molecular diversity and geographical origin of the landraces, which is indeed contrary to the findings of Zeid et al. (2003) for Northern and Southern Europe and North Africa, and Zong et al. (2009) for China, Europe, Africa, and other parts of Asia. The possible explanation for that is Palestine in general and the West Bank in particular "in which all landraces were collected" is a small geographical area, and therefore, we would expect a narrow genetic diversity of faba bean landraces. In addition, most of these landraces may have moved from one place to another through human activities (Kwon et al., 2010). However, only VF-22, VF-23, and VF-24 landraces, which were collected from the Bethlehem region were clustered together. Indeed, the similar agro-climate that characterizes the region may be the reason for showing more similarity with each other and therefore clustering together (Yadav et al., 2012). In addition, landraces of big seed sizes were also grouped together, which also implies high genetic similarities between them, and may belong to the same genotype. 


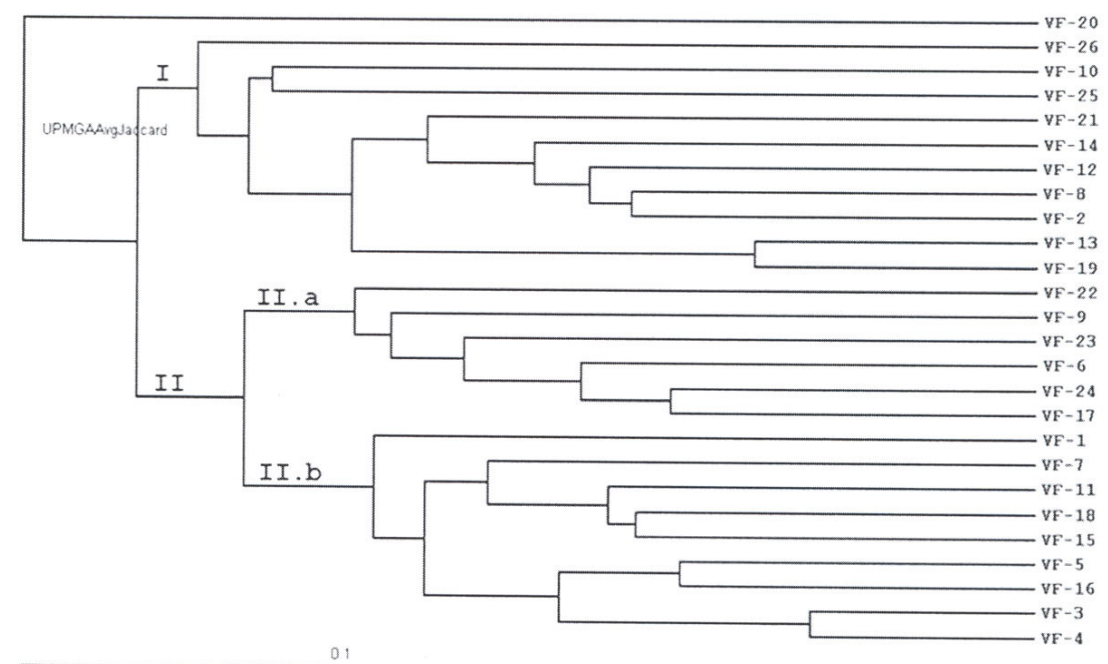

Figure 3. Dendrogram of 26 Palestinian faba bean landraces constructed by unweighted pair-group method with arithmetic average (UPGMA) and based on randomly amplified polymorphic DNA (RAPD) banding patterns.

\section{ACKNOWLEDGMENTS}

We gratefully thank Dr. David Vagnoni (Faculty of Agriculture, Hebron University, West Bank, Palestine) for reading the manuscript and providing helpful comments.

\section{REFERENCES}

Achtak H, Oukabli A, Ater M, Santoni S, et al. (2009). Microsatellite markers as reliable tools for fig cultivar identification. J. Am. Soc. Hortic. Sci. 134: 624-631.

Agarwal M, Shrivastava N and Padh H (2008). Advances in molecular marker techniques and their applications in plant sciences. Plant Cell Rep. 27: 617-631.

Basheer-Salimia R, Awad M and Ward J (2012). Assessments of biodiversity based on molecular markers and morphological traits among west-bank, palestine fig genotypes (Ficus carica L.). Am. J. Plant Sci. 3: 1241-1251.

De Giorgio D and Polignano GB (2001). Evaluating the biodiversity of almond cultivars from germplasm collection field in southern Italy. Sust. Glob. Farm. 56: 305-311.

FAO (2010). Database of the Food and Agricultural Organization (FAO) of the United Nations. Available at [http://www. fao.org]. Rome.

Gilbert JE, Lewis RV, Wilkinson MJ and Caligari PDS (1999). Developing an appropriate strategy to assess genetic variability in plant germplasm collections. Theor. Appl. Genet. 98: 1125-1131.

Gnanasambandam A, Paull J, Torres A, Kaur S, et al. (2012). Impact of molecular technologies on faba bean (Vicia faba L.) breeding strategies. Agronomy 2: 132-166.

Gresta F, Avola G, Albertini E, Raggi L, et al. (2009). A study of variability in the Sicilian faba bean landraces 'Larga di Leonforte'. Genet. Res. Crop Evol. 57: 523-531.

Kaser HR and Steiner AM (1983). Subspecific classification of Vicia faba L. by protein and isozyme patterns. FABIS Newsl. 7: 19-20.

Kaur S, Pembleton LW, Cogan NO, Savin KW, et al. (2012). Transcriptome sequencing of field pea and faba bean for discovery and validation of SSR genetic markers. BMC Genomics 13: 104.

Kocsis M, Jaromi L, Putnoky P, Kozma P, et al. (2005). Genetic diversity among twelve grape cultivars indigenous to the Carpathian basin revealed by RAPD markers. Vitis 44: 87-91. 
Kuckuck H, Kobabe G and Wenzel G (1991). Fundamentals of Plant Breeding (1st edn.). Springer-Verlag, Heidelberg, Berlin.

Kumar A and Ali M (2006). GE interaction and its breeding implications in pulses. Botanica 56: 31-36.

Kwon SJ, Hu J and Coyne CJ (2010). Genetic diversity and relationship among faba bean (Vicia faba L.) germplasm entries as revealed by TRAP markers. Plant Genet. Resour. 8: 204-213.

Link W, Dixkens C, Singh M, Schwall M, et al. (1995). Genetic diversity in European and Mediterranean faba bean germplasm revealed by RAPD markers. Theor. Appl. Genet. 90: 27-32.

Mancini R, De Pace C, Scarascia Mugnozza GT, Delre V, et al. (1989). Isozyme gene markers in Vicia faba L. Theor. Appl. Genet. 77: 657-667.

Mc-Vicar R, Panchuk K, Brenzil C, Hartley S, et al. (2008). Faba Bean in Saskatchewan. Saskatchewan Ministry of Agriculture. Available at [http://www.agriculture.gov.sk.ca/adx/aspx/adxGetMedia.aspx?DocID=1070,335,185,81, 1,Documents\&MediaID=5743\&Filename=Faba+Bean+in+Saskatchewan+-+Printer+Friendly.pdf].

Murray GA, Wser D, Gusta LV and Eteve G (1988). World Crops: Cool Season Food Legumes. (Summerfield RJ, ed.). Kuwer, London, 831-843.

PCBS (2010). Database of the Palestinian Central Bureau of Statistics. Available at [http://www.pcbs.gov.ps].

Prevost A and Wilkinson MJ (1999). A new system of comparing PCR primers applied to ISSR fingerprinting of potato cultivars. Theor. Appl. Genet. 98: 107-112.

Redden R, Zong X, van Leur J, Wang S, et al (2007). Increased Productivity of Cool Season Pulses in Rain-Red Agricultural Systems of China and Australia. Final Report ACIAR Project: CSI/2000/035.

Schluter PM and Harris SA (2006). Analysis of multilocus fingerprinting data sets containing missing data. Mol. Ecol. Notes 6: 569-572.

Schmidtke K and Rauber R (2000). Grain legumes and nitrogen cycling in organic crop systems. Grain Legumes 30: 1617.

Terzopoulos PJ and Bebeli PJ (2008). Genetic diversity analysis of Mediterranean faba bean (Vicia faba L.) with ISSR markers. Field Crops Res. 108: 39-44.

Torres AM, Weeden NF and Martín A (1993). Linkage among isozyme, RFLP and RAPD markers in Vicia faba L. Theor. Appl. Genet. 85: 937-945.

Yadav K, Yadav SK, Yadav A, Pandey VP, et al. (2012). Genetic diversity of Pigeonpea (Cajanus cajan L.) Millsp.) cultivars and its wild relatives using randomly amplified polymorphic DNA (RAPD) markers. Am. J. Plant Sci. 3: 322-330.

Yahia Y, Guetat A, Elfalleh W, Ferchichi A, et al. (2012). Analysis of agro-morphological diversity of southern Tunisia faba bean (Vicia faba L.) germplasm. Afr. J. Biotechnol. 11: 11913-11924.

Zeid M, Schon CC and Link W (2003). Genetic diversity in recent elite faba bean lines using AFLP markers. Theor. Appl. Genet. 107: 1304-1314.

Zong X, Liu X, Guan J, Wang S, et al. (2009). Molecular variation among Chinese and global winter faba bean germplasm. Theor. Appl. Genet. 118: 971-978. 